\title{
English Auctions with Toeholds: An Experimental Study
}

\author{
Sotiris Georganas* and Rosemarie Nagel ${ }^{\dagger}$
}

July 3,2008

\begin{abstract}
We run experiments on English Auctions where the bidders already own a part (toehold) of the good for sale. The theory predicts a very strong effect of even small toeholds, however we find the effects are not so strong in the lab. We explain this by analyzing the flatness of the payoff functions, which leads to relatively costless deviations from the equilibrium strategies. We find that a levels of reasoning model explains the results better than the Nash equilibrium. Moreover, we find that although big toeholds can be effective, the cost to acquire them might be higher than the strategic benefit they bring. Finally our results show that in general the seller's revenues fall when the playing field is uneven.
\end{abstract}

JEL codes: D44, C91, G34

keywords: experiments, toehold auction, takeover, payoff flatness, quantal response, level-k

*Ohio State University, georganas.1@osu.edu.

${ }^{\dagger}$ Universitat Pompeu Fabra, rosemarie.nagel@upf.edu. We thank Jordi Brandts, John Kagel, Dan Levin, Reinhard Selten and Nan Li for stimulating discussions and comments. We also thank seminar participants at the Econometric Society NASM 2008, the 2007 ESA conference in Rome and the EDP Jamboree in Louvain. Nagel acknowledges the financial support of the Spanish Ministry of Education under Grant SEJ2005-08391 and thanks the Barcelona Economics Program of CREA. Georganas thanks the hospitality of Universitat Pompeu Fabra and the financial support of Nagel's distinció de la Generalitat de Catalunya. 


\section{Introduction}

Competition for the control of a company can be essentially viewed as an ascending auction. The bidders in such an auction have more or less similar valuations for the contested company. This leads to the literature often viewing such takeover battles as common value auctions. While there is a strong common value element in these auctions there very often exist small asymmetries which can radically change the strategic interplay between the bidders and the outcome of the contest.

If the asymmetries are due to some private control benefits or idiosyncratic synergies then we can speak of almost common value auctions (Klemperer 1998), auctions where one of the bidders has a small payoff advantage, a value that is slightly higher than the common value. The asymmetries can also arise when some bidders already own a part of the company that is being sold. Ownership of such a part is called a toehold and is quite common in takeover battles (Betton and Eckbo 2000). This paper presents results from experiments on auctions with toeholds and compares these results with the theory and other experimental results in almost common value auctions.

In theory ownership of a toehold can deter competitors from bidding for the company and can give its owner a strong strategic advantage. Bulow et al. (1999) give a good illustration of how toeholds can be useful in takeover battles. The authors use an English auction framework, where bidders for a company have similar restructuring plans but differing estimates of the expected returns. Under this setup, the buyers have common values but imperfect signals. The analysis proceeds to find that with common values, toeholds can have a profound effect on players' optimal strategies. Players with a toehold bid more aggressively as they know they will not have to pay the full price and in the case they lose they will get part of this payment. On the other hand players facing an opponent who owns a toehold, have to play less aggressively than in the case the playing field were level. In equilibrium, even with a small toehold of $5 \%$ or $10 \%$ the bidder who owns it will get the company for a much lower price than without toeholds. Thus, theory gives strong reasons for bidders to acquire toeholds. The empirical findings however are not in full support of this idea. Betton and Eckbo (2000) find that only about half of the bidders acquire toeholds before trying to buy a majority stake.

Our paper addresses the conflict between this observation and theoretical results. Although theory predicts that the toeholds should have a big effect on the players' predicted strategies, 
the effect could be much smaller when human players participate in this game, for reasons that will become clear in the analysis. Thus we designed and ran a series of experiments to test this idea. We choose an English auction with two players and common values, similar to the Bulow et al. (1999) setup. The major simplification is that we let the total value simply be the sum of the signals the players receive. This is to keep the setup simple and to avoid understanding problems on behalf of the players. What we found is indeed that although toeholds give bidders an advantage, it is not nearly as strong as theory predicts. Thus, under some circumstances it is not advisable for an agent planning a takeover to acquire toeholds. Moreover, we find that the players' deviation from the theoretical prediction is not unreasonable, but rather has deep roots in the structure of the equilibrium proposed by Bulow et al (1999). The equilibrium payoff functions are in some cases extremely flat, meaning that large deviations from equilibrium are practically costless. In particular, we find that when the ratio of the two players toeholds is larger than 10 (e.g. $1 \%$ and 10\%), the strong bidder can deviate almost $50 \%$ from his optimal bid with a negligible loss in expected payoff. Consequently, there is no reason to believe that human agents - be it in the lab or in real markets - would play their exact best responses and thus convergence to the theoretical equilibrium is very unlikely. We show that a levels-of-reasoning model (Nagel 1995, Stahl and Wilson 1995, Crawford and Iriberri 2008) which assumes bounded rationality of the players generates more intuitive predictions and fits the observed behaviour more precisely.

To our knowledge there are no other experimental studies focusing on toeholds. There are however models with almost common values that as mentioned above lead to similar theoretical results (see for example Kagel and Levin 2003). When a player is known to enjoy a payoff advantage in a common value auction, theory predicts an explosive effect in the bidding strategies, similarly to the effect of toeholds. The player with the advantage bids more aggressively, his opponents less, which leads to the strong player winning almost all the time. Avery and Kagel (1997) have sought to test this theory and they found that the differences in common values have a linear and not explosive effect. Moreover, they find advantaged bidders' behaviour resembles a best response to the behaviour of disadvantaged bidders. The latter bid much more aggressively than in equilibrium, which leads to negative average profits. Experienced players bid consistently closer to the Nash equilibrium than inexperienced bidders, although these adjustments towards equilibrium are small.

In a recent paper with a similar setup, Kagel and Rose (2006) again find that the Nash prediction 
fails to prognose the subjects' behaviour. They find rather that behaviour is characterized by a behavioral model where the advantaged bidders simply add their private value to their private information signal about the common value, and proceed to bid as if in a pure common value auction. The model they chose is actually, as we shall see later, a special case of the more general toehold framework. The main theoretical difference between their model and ours is that the high types should win the auction with probability one in the almost common value setting, while in our experiments the effect is predicted to be much weaker.

While our paper finds no explosive effect of small asymmetries, similarly to the above papers, our design has the advantage of varying toehold differences which allow us to see if the comparative statics predicted by theory hold, even when subjects are not following exactly the equilibrium strategies. Our finding is that in general weak types tend to bid less aggressively the higher the toehold difference, which is only partially in accordance with the theory but much more consistent with the predictions of the levels of reasoning model.

Section 2 introduces the model. Section 3 presents the experimental setup and Section 4 analyzes the data. Section 5 concludes.

\section{The model}

Two risk neutral bidders $i$ and $j$ bid in an English auction for one unit of an indivisible good. Bidders' signals $t_{k}$ are independently drawn from the uniform distribution in $[0,1]$. The value of the good to every bidder is then just the sum of these signals. Additionally the bidders already own a share of the company $\theta_{k}$, which we will call a toehold. Ownership of a toehold means that in case the company is sold the owner will get $\theta_{k}$ times the sale price, thus if she wins she only pays $1-\theta_{k}$. Bidder's shares are exogenous and common knowledge.

The unique symmetric equilibrium is calculated in Bulow et al. (1999).

Proposition 1 The equilibrium bidding functions of the game are given by

$b_{i}\left(t_{i}\right)=2-\frac{1}{1+\theta_{j}}\left(1-t_{i}\right)-\frac{1}{1+\theta_{j}}\left(1-t_{i}\right)^{\frac{\theta_{i}}{\theta_{j}}}$

A discussion and the proofs can be found in the aforementioned paper.

The proposition is true for all $\theta>0$. For $\theta=0$ we would have a usual English auction with 
common values, with the well known equilibria. That is, in the absence of toeholds the equilibrium bidding functions would be just symmetric, straight lines ${ }^{1}$ through the origin with slope 2. Even when players have toeholds, if they are symmetric, the bidding functions are still symmetric straight lines with a slope that depends on $\theta$.

Now, when the toeholds are asymmetric there is the explosive effect described in the introduction. The bidding functions of the two players grow apart very rapidly. In Figure 1 you can see the shapes of the equilibrium bidding functions, separately for the low and high types. It can be observed that for toehold differences greater than 10 percentage points, the functions have parts with extremely high slopes. For signals close to 0 the high types' bids rise very steeply and similarly for signals close to 100 the low types' functions are rising very fast.

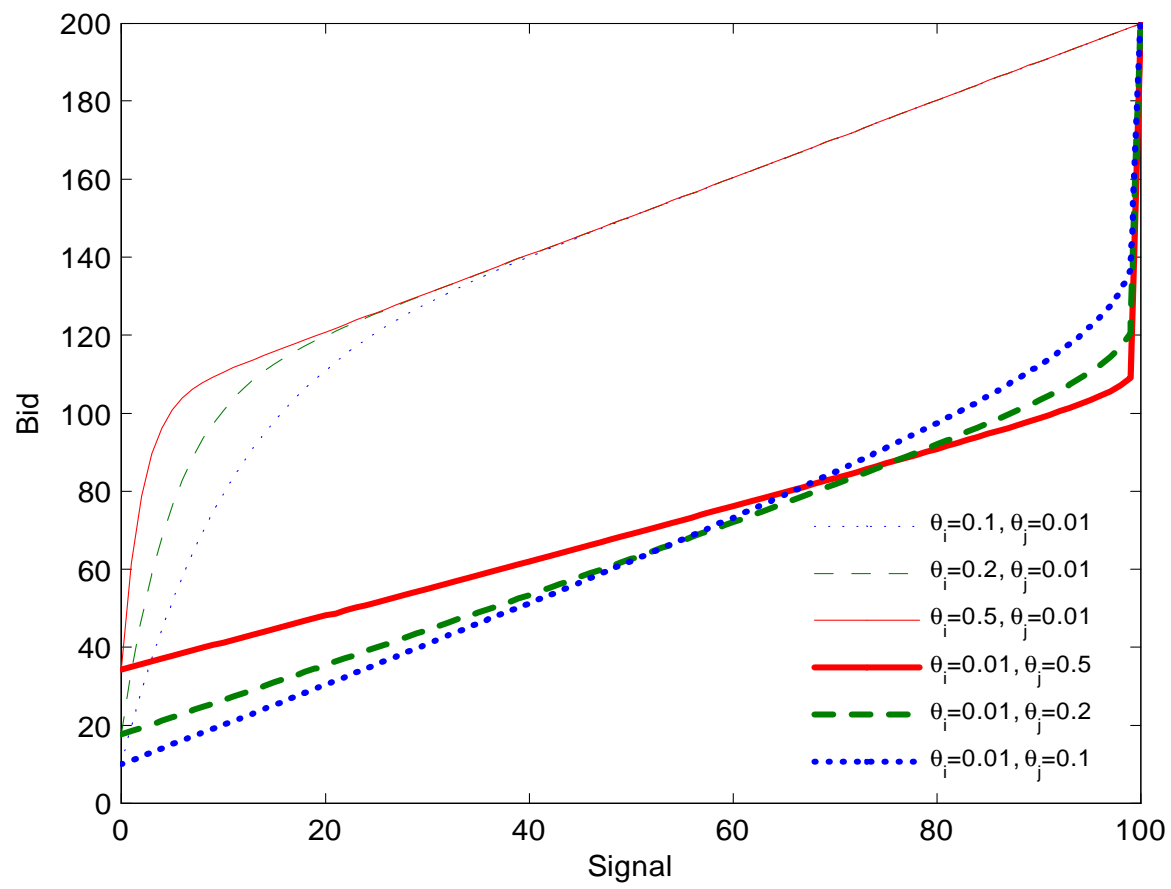

Figure 1: The equilibrium bidding functions for $\theta_{i}=0.01$ and $\theta_{j}=0.05,0.2$ and 0.5 . The lower thick lines represent the bids of the low toehold type, the upper thin lines are the bids of the high type.

Observe that the bidder with the large toehold bids for every possible signal more than in the symmetric case where no bidder has a toehold. On the other hand, the bidder with the smaller

\footnotetext{
${ }^{1}$ This can be seen by the standard methods used in the literature. There is however a more straightforward way to see what happens for very small toeholds, by taking the limit of the bidding function in proposition 1 with the toeholds being equal and tending to zero. The function then reduces to just $b(t)=2 t$.
} 
toehold bids lower than in the symmetric case for almost all but the smallest values of her signal. Finally it is obvious from the figure that when the difference between the toeholds becomes larger, the high type tends to become more aggressive for all signals he can get. The low type tends to bid less aggressively for almost all of her possible signals.

Results from the theoretical paper that will be useful for our analysis are

a) the probability of winning the auction for agent $i$ is just $\theta_{i} /\left(\theta_{i}+\theta_{j}\right)$

b) increasing a bidder's toehold always makes the bidder more aggressive.

c) increasing a bidder's toehold increases her profits regardless of her signal.

\section{$3 \quad$ The experimental setup}

The experiments were run with undergraduates of all faculties in the LeeX of the Universitat Pompeu Fabra, in Barcelona. No subject could participate in more than one session. Upon arrival students were randomly assigned to their seats. One of the instructors read the instructions aloud and questions were answered in private. Sessions lasted about 1 hour including the reading of the instructions. All sessions presented here were run by computer using z-tree tools (Fischbacher 2007).

Our design consisted of three treatments with two players, one owning a low toehold and the other owning a high toehold. The low toehold was always equal to $1 \%$, the high toeholds were equal to $5 \%, 20 \%$ and $50 \%$ respectively. We had one session of the combination $1 \%-5 \%$ (hence treatment 1-5), two sessions of 1\%-20\% (treatment 1-20) and three sessions of 1\%-50\% (treatment 1-50). Players alternated roles every turn ${ }^{2}$ and the assignment of the toeholds was common knowledge. Note that the treatments we chose are representative of all cases where the toeholds have a ratio of $1 / 5,1 / 20$ and $1 / 50$. This means treatments $1-20$ and $1-50$ should not be dismissed as extreme cases that have no practical relevance. ${ }^{3}$

Each session consisted of 16 subjects, which were divided into 2 independent subgroups of

\footnotetext{
${ }^{2}$ We had the players alternate roles because of the big asymmetry induced by the toeholds. Theoretically the low toehold types were predicted to make close to zero profits in treatments 1-20 and 1-50!

${ }^{3}$ For the bidding strategies the ratio of the toeholds is of big significance, but the absolute size of the toeholds plays a much smaller role. It is easy to see that the predicted bidding functions are virtually identical between the case of 1-20 and other cases with the same toehold ratio. This includes for example cases that are more frequently found in the field, such as toeholds of $0.1 \%$ and $2 \%$. The toehold configuration of 1-20 and 1-50 was chosen in order to make computations easier for the subjects.
} 
8 subjects. This way we obtain two independent observations for each session. Each session consisted of 50 rounds. In each round or period, a signal between 1 and 100 was drawn randomly and independently for every bidder. Subsequently the players participate in an English auction. This means they had in their screen a clock that was constantly ticking upwards. Bidders were considered to be actively bidding until they pressed a key to drop out of the auction. Once they dropped out, they could not re-enter the auction. As usual in English auctions, when all but one players have exited the auction stops. Since we had only two players, once one of them dropped out, the auction ended and the other player was assigned the good. The winner was payed the common value (sum of the two values of the two players) and had to pay the price shown in the clock. Additionally every player received her portion of the price according to her toehold. The information feedback the players received after every round was the value of the asset, the selling price, whether she was the buyer of the asset or not, the gain/loss that she made if she was the buyer of the asset or the gain/loss that she made if she was not the buyer of the asset. Players were given some time to review this information before going to the next round. After every round subjects were randomly matched with the next opponent.

During the experiment, subjects were always able to check the History of the last six rounds they played, with all the relevant information. The rest of the rounds were viewable by using a scroll bar.

The currency of the experiment were Thalers. At the outset of the experiment, each of the subjects received a capital balance of 1000 Thalers. Total gain from participating in this experiment was equal to the sum of all the player's gains and her capital balance minus her losses. If ever the player's gains fell below 0, she would not be allowed to participate any more. Fortunately this did not happen. At the end of the experiment the gains were converted to pesetas at the rate of 1.5 pesetas per Thaler ${ }^{4}$.

\section{Experimental results}

The main question we are trying to answer is to what extent owning a toehold alters the strategic behaviour of a bidder in an English auction. Then we want to see if this change in behaviour is

\footnotetext{
${ }^{4}$ The peseta has meanwhile given its place to the euro. One euro corresponds to approximately 166 pesetas.
} 
translated into a difference in prices.
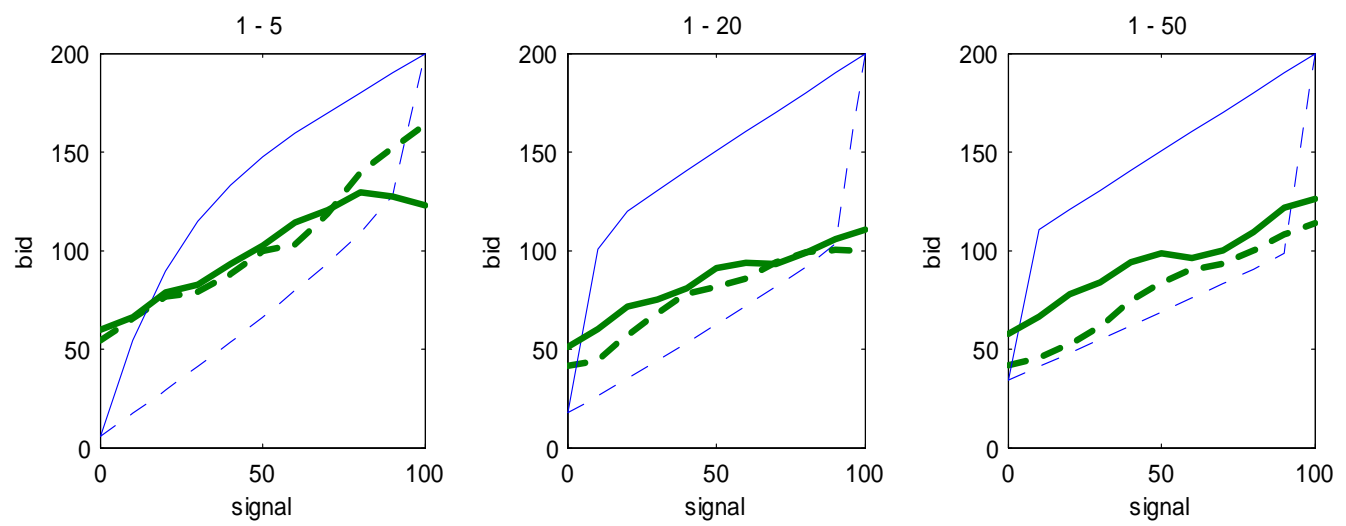

Figure 2: Actual (thick lines) vs theoretical bid functions (thin lines) in the three treatments. The dotted lines represent bids of the low type, solid lines are bids of the high type.

We start with the strategies. In Figure 2 we have plotted the average exits for the three treatments for given signals ${ }^{5}$. Furthermore, we plot the equilibrium bids of all players. Clearly for the treatment 1-5 and there seems to be no difference in behavior between the two types. For treatments 1-20 and 1-50 high types bid more than low types. Players in general do not follow the shape of the equilibrium bidding functions ie, bidding seems to be linear instead of the highly convex and concave shapes of the equilibrium bids.

Players do not even seem to be influenced by the toehold, when it is low, as can be seen from the fact that in Treatment 1-5 the low toehold type wins approximately half the time, when theoretically she should win only $17 \%$ of the time. These results are presented in Table 1 . Note that although the signals were drawn at random, the theoretical ex post winning possibilities are close to the ex ante ones ${ }^{6}$ of $1 / 6$ for treatment $1-5,1 / 21$ for $1-20$ and $1 / 51$ for treatment $1-50$. In treatment 1-20 the low toehold type still wins more often than she should, and the discrepancy between the theoretical frequency and the predicted one is slightly bigger. In treatment 1-50 the discrepancy between the theoretical winning frequency and the empirical one is smaller. However it has to be noted that the low type should win only about $1.5 \%$ of the time, while actually she won in $33.8 \%$ of the cases!

In total, there seems to be a tendency for the low toehold type to win less often, the higher the

\footnotetext{
${ }^{5}$ For graphs with details for every individual experiment see Appendix.

${ }^{6}$ Recall from section 2 that the ex ante probability of player $i$ winning is $\theta_{i} /\left(\theta_{i}+\theta_{j}\right)$.
} 


\begin{tabular}{llll}
\hline \hline & Observation & should win & won \\
\hline Treatment 1-5 & 1 & 0.2 & 0.48 \\
& 2 & 0.135 & 0.54 \\
treatment average & & $\mathbf{0 . 1 6 7}$ & $\mathbf{0 . 5 1}$ \\
\hline Treatment 1-20 & 3 & 0.055 & 0.495 \\
& 4 & 0.045 & 0.39 \\
& 5 & 0.015 & 0.495 \\
treatment average & 6 & 0.04 & 0.425 \\
Treatment 1-50 & 7 & $\mathbf{0 . 0 3 8}$ & $\mathbf{0 . 4 5 1}$ \\
& 8 & 0.01 & 0.37 \\
& 9 & 0.02 & 0.36 \\
& 10 & 0.03 & 0.255 \\
& 11 & 0.015 & 0.345 \\
treatment average & 12 & 0 & 0.385 \\
\hline \hline
\end{tabular}

Table 1: Win Frequency of the low type: Theoretic vs Actual

toehold of her opponent. This means naturally that a higher toehold, brings a higher chance of winning, both theoretically and in the experiments. However this effect of the toehold on bidding behaviour is not very clear, so we try to estimate its statistical significance. Note, that it is an inherent characteristic of an English auction that we cannot observe the intended bids of the winners, as the winner exits the auction automatically once the one but last bidder leaves. To overcome this we use tobit techniques, or censored regressions (see Kirchkamp, Moldovanu 2004) to estimate these unobserved bids. The regression we estimated was

$$
\operatorname{Bid}=\text { constant }+\alpha^{*} \text { value }+\beta^{*} \text { toehold }+\varepsilon
$$

We run this regression for each independent observation. Note the toehold variable is not a binary dummy, but equals the value of the toehold $(1,5,20$ or 50). We add a dummy for the period variable, to control for learning effects. There seemed to be some learning in the first 5 to 10 periods. We always excluded these first 10 periods from the subsequent analysis. Other factors we tried in the analysis, like cubic or interaction terms were not significant and thus are not presented. The results of the regressions for the various treatments are summarised in Table 2.

In parentheses is the number of observations where the coefficient was significant and the asterisks denote the level of significance. Note that the toehold dummy is equal to 5, 20 and 50 in the relevant cases. We observe that in treatment 1-5 the possession of a higher toehold makes almost 


\begin{tabular}{lllll}
\hline \hline Treatment & constant & value & toehold & mean $\mathbf{R}^{2}$ \\
\hline $1-5$ & 55.876 & 1.08 & 0.74 & 0.67 \\
$\sigma$ & 3.82 & 0.06 & 0.79 & \\
& $(2 / 2)$ & $(2 / 2)$ & $\left(1^{*} / 2\right)$ & \\
$1-20$ & 49.53 & 0.84 & 0.365 & 0.51 \\
$\sigma$ & 4.15 & 0.07 & 0.19 & \\
& $(4 / 4)$ & $(4 / 4)$ & $\left(2^{* *} / 4\right)$ & \\
$1-50$ & 43.92 & 0.887 & 0.51 & 0.60 \\
$\sigma$ & 3.88 & 0.068 & 0.08 & \\
& $(6 / 6)$ & $(6 / 6)$ & $\left(6^{* * *} / 6\right)$ & \\
\hline \hline
\end{tabular}

Table 2: Results of the tobit regressions. There was one regression for each independent session. Numbers in parentheses are significant cases out of total. In treatment 1-5 the one asterisk means that one observation was significant at the 0.1 level. In 1-20 there were two significant observations, both at 0.05. In 1-50 all cases were significant at the 0.01 level.

no difference for the subjects' bidding behaviour. However, in 1-20 the toehold sometimes has a significant effect. On average, the high toehold type bid $0.365^{*} 20=6.94$ more than the low toehold type. In 1-50 the effect of the toehold is always significant and quite high. The high toehold type will bid on average 24.99 more than the low toehold type.

Now, for economic applications it is interesting to see how this difference in the bidding behaviour translates into auction prices. If the different bidding behaviour were to result in similar prices as theoretically predicted, then our results would show that the theory is valid for all practical purposes where the prices are the point of interest. As we can see in Figure 3 this is not the case.

The unique equilibrium predicts ${ }^{7}$ prices should fall slightly with the high type getting a toehold 20 instead of 5 . This is reflected in our data. The mean price in treatment $1-5$ was 89.7 , in treatment 1-20 it was much lower at 73.8. Going from a high type with toehold 20 to the high type having 50 , the prices were expected to rise by more than $10 \%$, but they only rose to 76.9 which is a $4.2 \%$ rise. In general our results mean that ceteris paribus the seller's revenues will tend to fall when there exist players with larger toeholds.

Interestingly the deviation of actual prices from the theoretical ones tended to fall the higher the toehold. Actual mean deviations over all periods were 28 for treatment 1-5, 14 for treatment 1-20 and 8 for treatment 1-50. Note of course that when calculating the mean, positive and negative deviations tend to cancel out. This is why it seems useful to have a look at Figure 4, where we

\footnotetext{
${ }^{7}$ The a priori expected price is $\frac{\theta_{j}\left(2 \theta_{j}+\theta_{i}+1\right)}{\left(\theta_{j}+1\right)\left(2 \theta_{j}+\theta_{i}\right)}+\frac{\theta_{i}\left(2 \theta_{i}+\theta_{j}+1\right)}{\left(\theta_{i}+1\right)\left(2 \theta_{i}+\theta_{j}\right)}$, which gives us $63.1,62.8$ and 69.2 for treatments 1-5, 1-20 and 1-50 respectively. For our purposes however we use the theoretical prices given the actual values that the players had, so there is a small difference.
} 

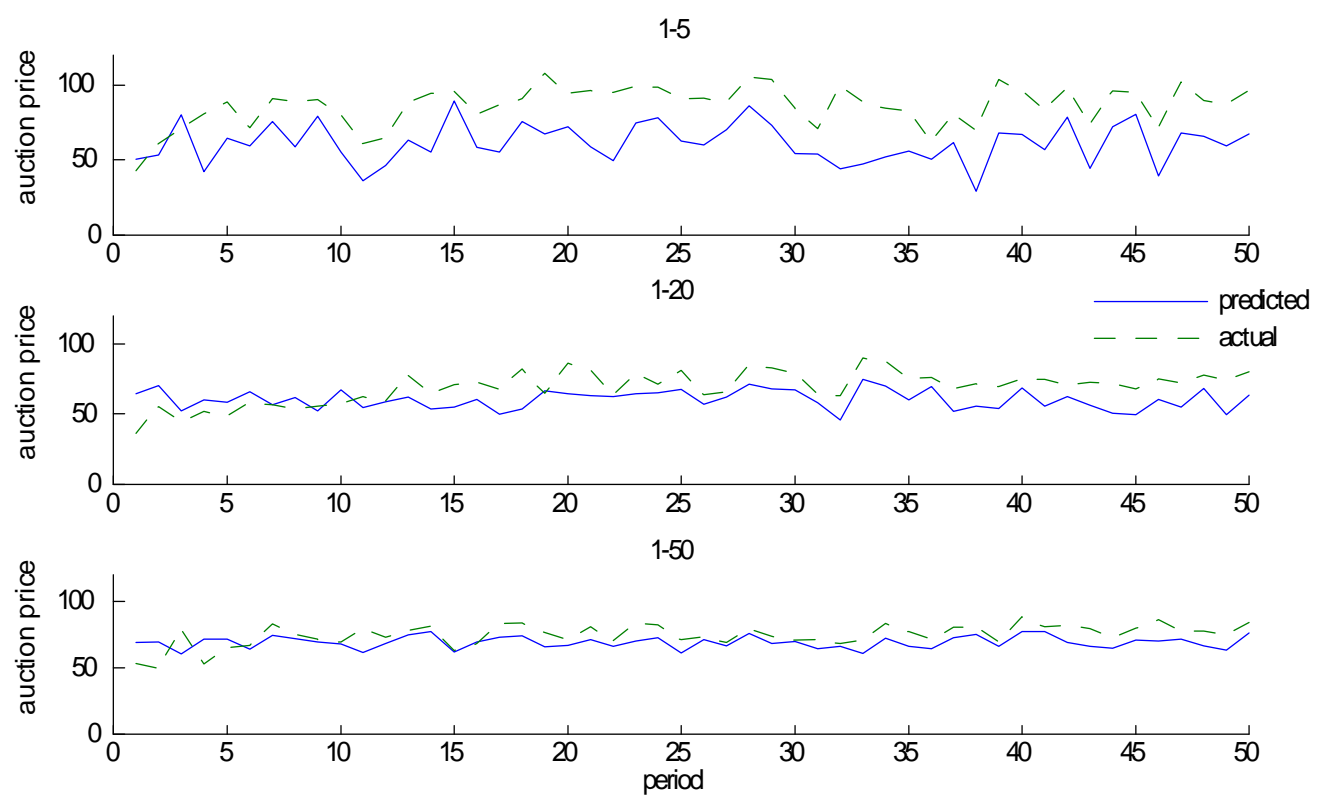

Figure 3: Predicted and actual prices over time in the three treatments.

present the evolution of the deviation of observed prices from the equilibrium prices, over time and for the different treatments.

The deviation in prices seems to be highest in treatment 1-5, where prices were usually quite a bit higher than predicted by the theory. This is due to the fact that the low types bid more aggressively than they should. In treatments 1-20 and 1-50 the deviation becomes smaller, with a tendency for the deviation to be higher in treatment 1-20. This again can be explained by the fact that low toehold bidders in treatment 1-20 were a bit more aggressive. Table III summarizes these results.

\begin{tabular}{llll}
\hline \hline Treatment & Mean actual price & Mean predicted price & Mean deviation \\
\hline $1-5$ & 88.7 & 61 & 27.7 \\
$1-20$ & 73.8 & 60.3 & 13.5 \\
$1-50$ & 76.9 & 69.2 & 7.7 \\
\hline \hline
\end{tabular}

Table 3: Mean prices and deviations from the theoretical predictions, in the various treatments 


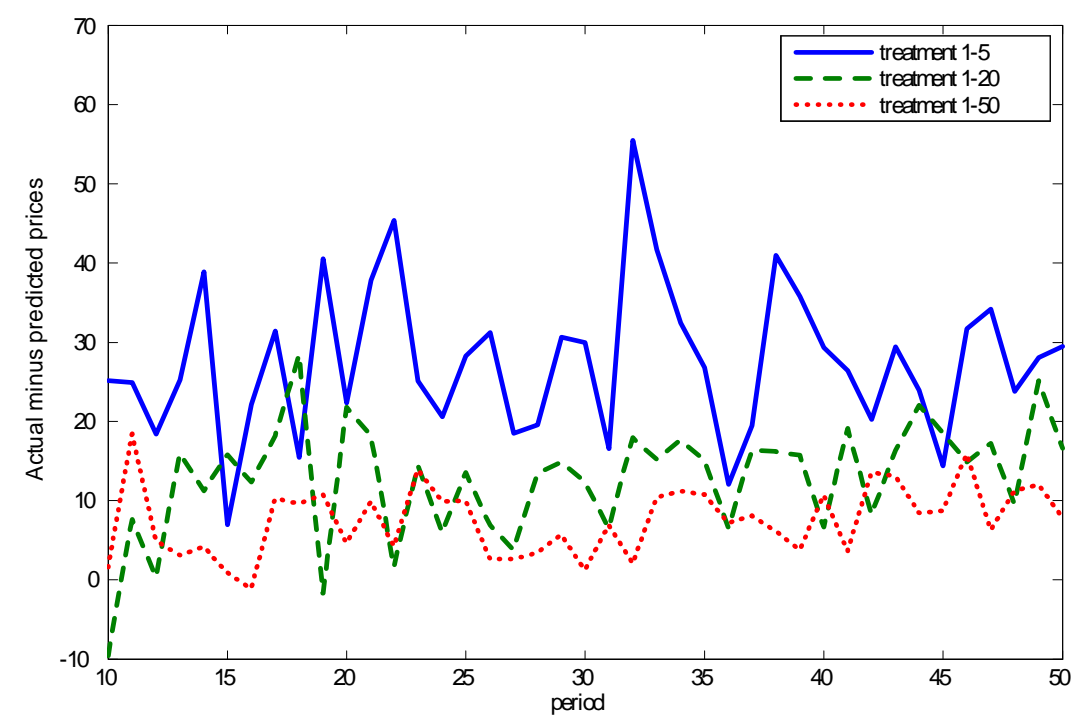

Figure 4: Deviation in average prices (actual minus predicted) over time for the three treatments.

\subsection{Theoretical analysis}

As we have seen in Figure 2, the subjects' behaviour constitutes a deviation with respect to the equilibrium prediction. Does this deviation evade any systematic rational analysis or are subjects responding to a feature of the game that was not obvious from the previous theoretical analysis? Our paper claims that the latter is the case.

There is some literature showing that we should not expect subjects to play the equilibrium strategies if a deviation from these does not cost very much (Harrison 1989). Players will make some small errors when bidding, which produces noise and this noise will be in some way indirectly proportional to the cost of a deviation (see for example McKelvey, Palfrey 1995). To examine this, we will calculate the equilibrium expected payoff functions for each type in every treatment. To be precise, the equilibrium expected payoff functions are the functions which depict one player's expected payoff depending on her bid. The expectation is taken over all possible signals of the opponent, given that this opponent will play the strategy predicted by the Nash equilibrium in Section 2 .

A closer look at these functions in our experiments, reveals that payoffs are very flat around the maximum. This means that a player anticipating the others to be in equilibrium, will not expect 
a big punishment for deviating from his equilibrium bid. Figure 5 visualises the concept. The different lines in each of the graphs in figure 5 are drawn for selected signals $(0,25,50,75,100)$ of a player with toehold 1 (graphs on the left) and those of a player with a high toehold (graphs on the right). The x-axis depicts a players bid and the y-axis the expected payoff given the behavior of the other type, and given the private signal $(0,25, \ldots, 100)$. As we can see for the low toehold type the expected payoff is near 0 in treatments 1-20 and 1-50 as theoretically the low type never wins. Additionally this flatness is growing with the difference in the toehold sizes ${ }^{8}$. This means the punishment for deviations is smallest in treatment 1-50, where it makes virtually no difference for the high toehold type if she bids even $50 \%$ less than the theoretical best response.
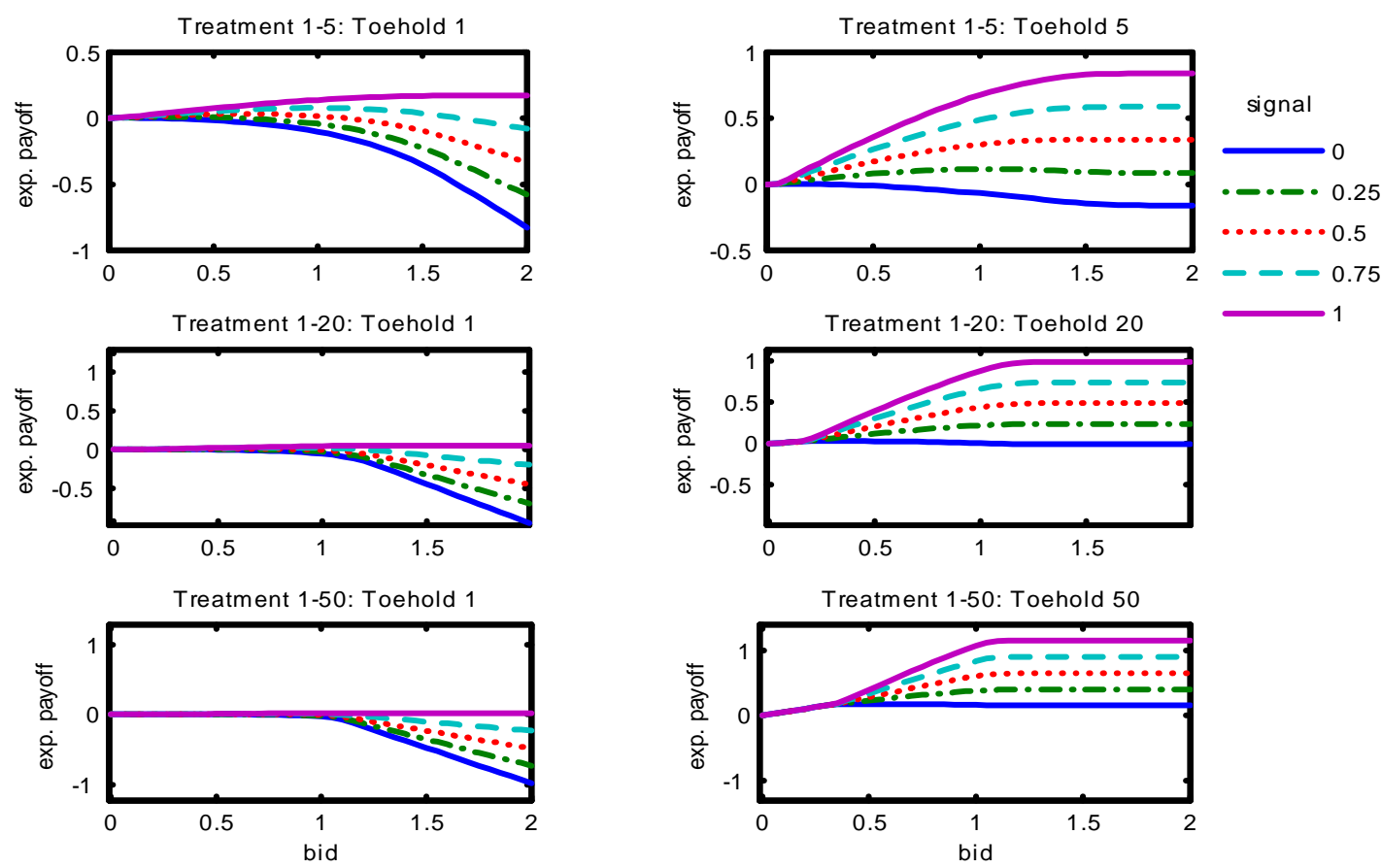

Figure 5: Payoff flatness in the various treatments. The various curves depict expected profits depending on bids (both scaled by 100) for signals 0, 25, 50, 75 and 100 given that the opponents play their equilibrium strategies.

The flatness we observe has a quite intuitive explanation and is a general feature of other auction models too, whenever parts of the bidding function are very steep. In the "explosive" equilibria predicted by theory the low types bid very defensively up to a very steep last part. In treatment

\footnotetext{
${ }^{8}$ Recall here that as explained in the design, our treatments are representative of a much wider class of possible configurations. This means that payoffs are flat not only in 1-20 and 1-50 but in all cases where the toehold ratio is greater than 20 .
} 
1-50 the low type bids less than 140 for almost all signals he gets. This means the high type has no big incentive to bid more than this value, as the probability of winning remains virtually unchanged. This flatness in the payoff functions can explain the difference between the results in our experiments and the usual results in common value English auctions, where bidders tend to follow their equilibrium strategies more closely. In common value English auctions, payoffs are not flat and the payoff maxima are quite pronounced. Thus bidders get stronger incentives to play the equilibrium strategies.

Now, given the flatness of the payoff functions it is interesting to investigate, how big was the deviation of our subjects in the payoff space $^{9}$ ? The reason is that although bid differences might be significant, they could lead to insignificant differences in payoffs, which is what really motivates subjects. Figure 6 illustrates the difference between actual and theoretical payoffs in all treatments.
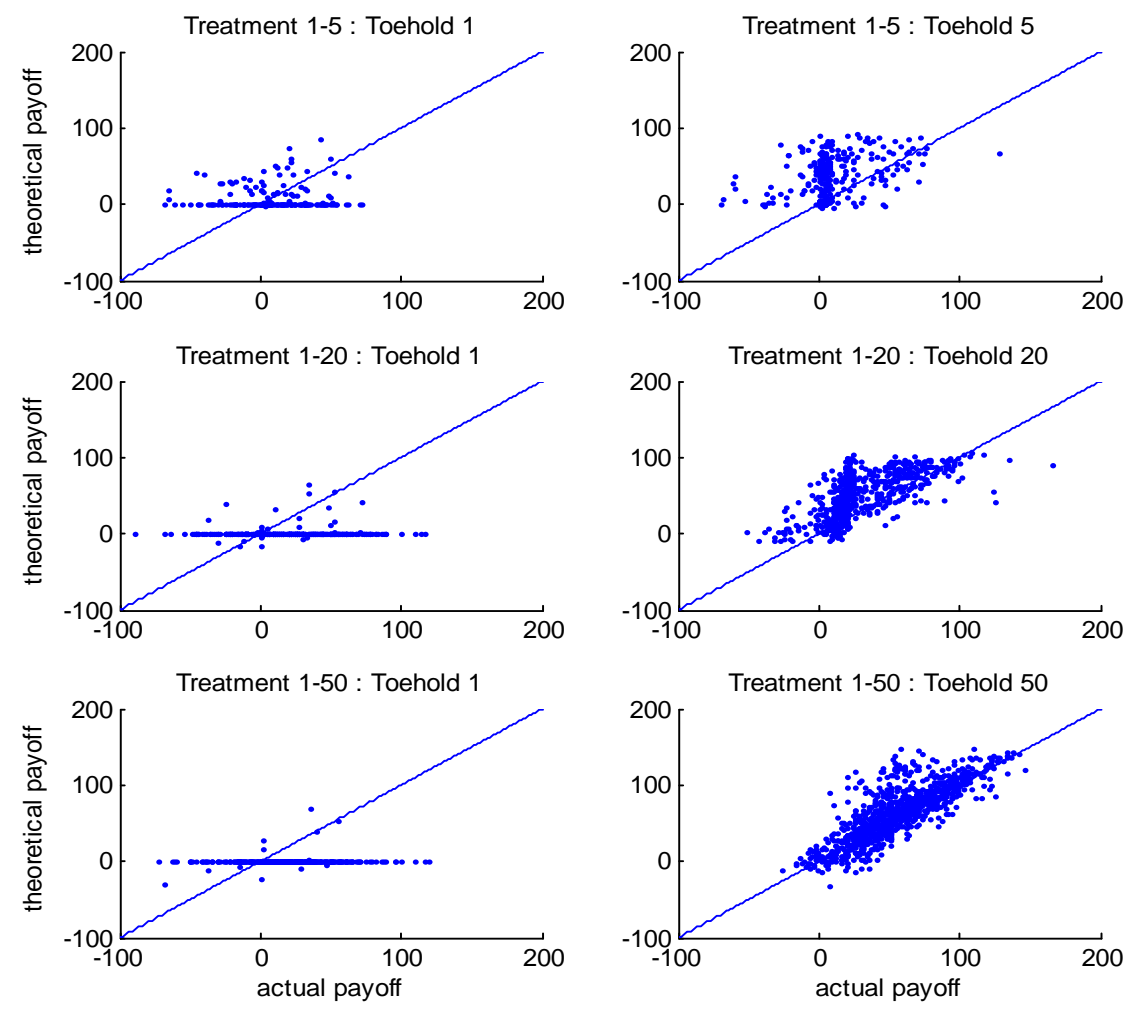

Figure 6: Actual vs Theoretical payoffs. The straight lines describe the equilibrium relationship.

If subjects' payoffs were close to the equilibrium payoffs all dots should lie close to the 45 degree

\footnotetext{
${ }^{9}$ According to many authors (eg Harrisson 91) this is the naturally relevant space to study.
} 
line. We see however that this is not the case. Only in some observations in Treatment 1-20 and in almost all observations in treatment 1-50 are the payoffs of the high type close to equilibrium. The payoffs of the low type are very often away from equilibrium. This is due to the fact that in Treatments 1-20 and 1-50 the low type sometimes wins the auction, although, as we have seen in table I, theoretically she should virtually never win!

So we see, bidders in our experiment had no incentives to play the equilibrium strategy. But their behaviour doesn't seem to be completely irrational. Their strategies were approximate best responses ${ }^{10}$ to the actual bidding behaviour of the others in treatments $1-5$ and 1-20, at least qualitatively as we can see in Figure 7 . The low toehold types bid more than predicted and the high types less, thus they converge to a middle ground.
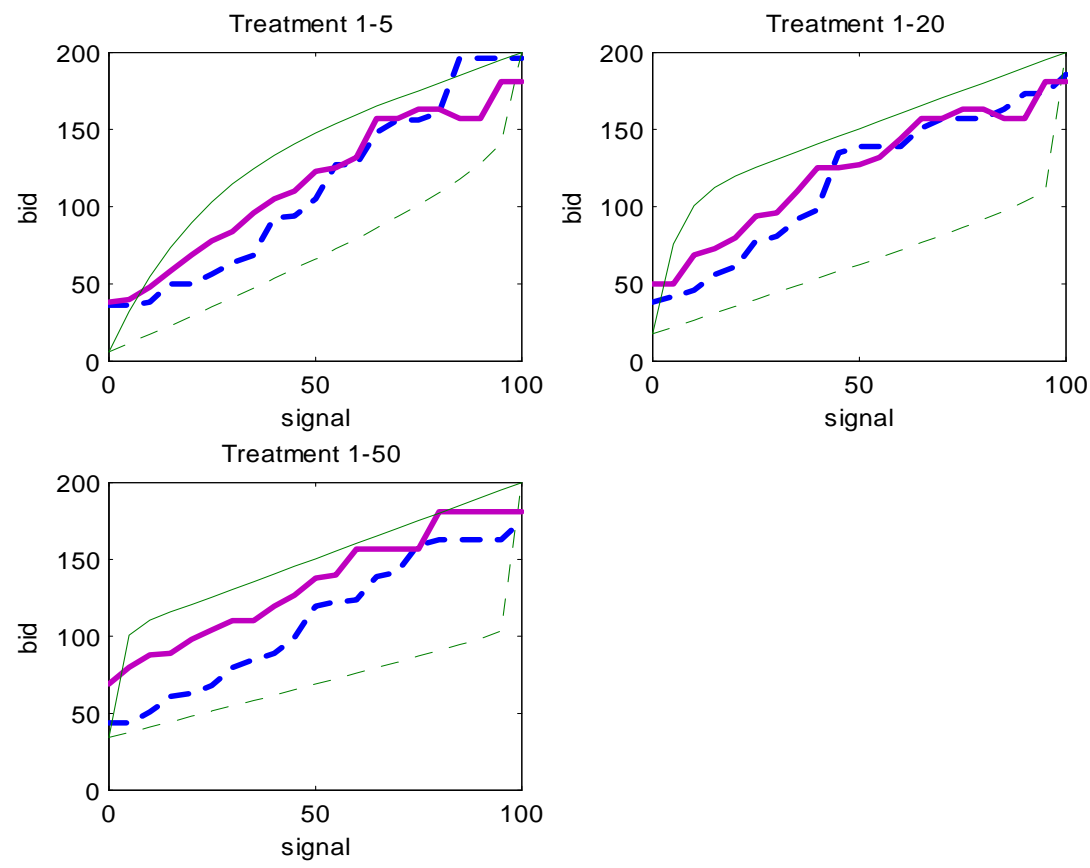

Figure 7: Best responses to actual bidding behaviour of the opponents. The dashed lines are the bids of the low type type, solid lines are bids of the high type. The thin lines depict the equilibrium best responses, while the thicker lines depict the best responses to the actual bid distributions.

It is worth noting that the best responses given actual behaviour are not very different between the low and the high type in the first two treatments and even the inter treatment difference is not

\footnotetext{
${ }^{10}$ We get the best responses by calculating the expected payoff given actual bids, and then maximising it. Actually, we calculated the average payoff for each bid in the sample when matched up with every other bid and signal value in the distribution, including that players other bids.
} 
high. Only in treatment 1-50 do we have a clear separation of the two types. Note that unlike in Kagel and Rose (2006), the high type would not have made a much higher profit in expectation, had he chosen the equilibrium bids instead of the actual ones. This is due to the substantial overbidding of the low types, which makes the option of winning less attractive to the high type than predicted by the equilibrium.

We also observe that the expected payoff functions are not so flat, if we calculate them this time assuming that the opponents' strategies follow the actual empirical distribution of the bids. This means that subjects now have higher incentives to play strategies that resemble their best responses. This is visualised in Figure 8.
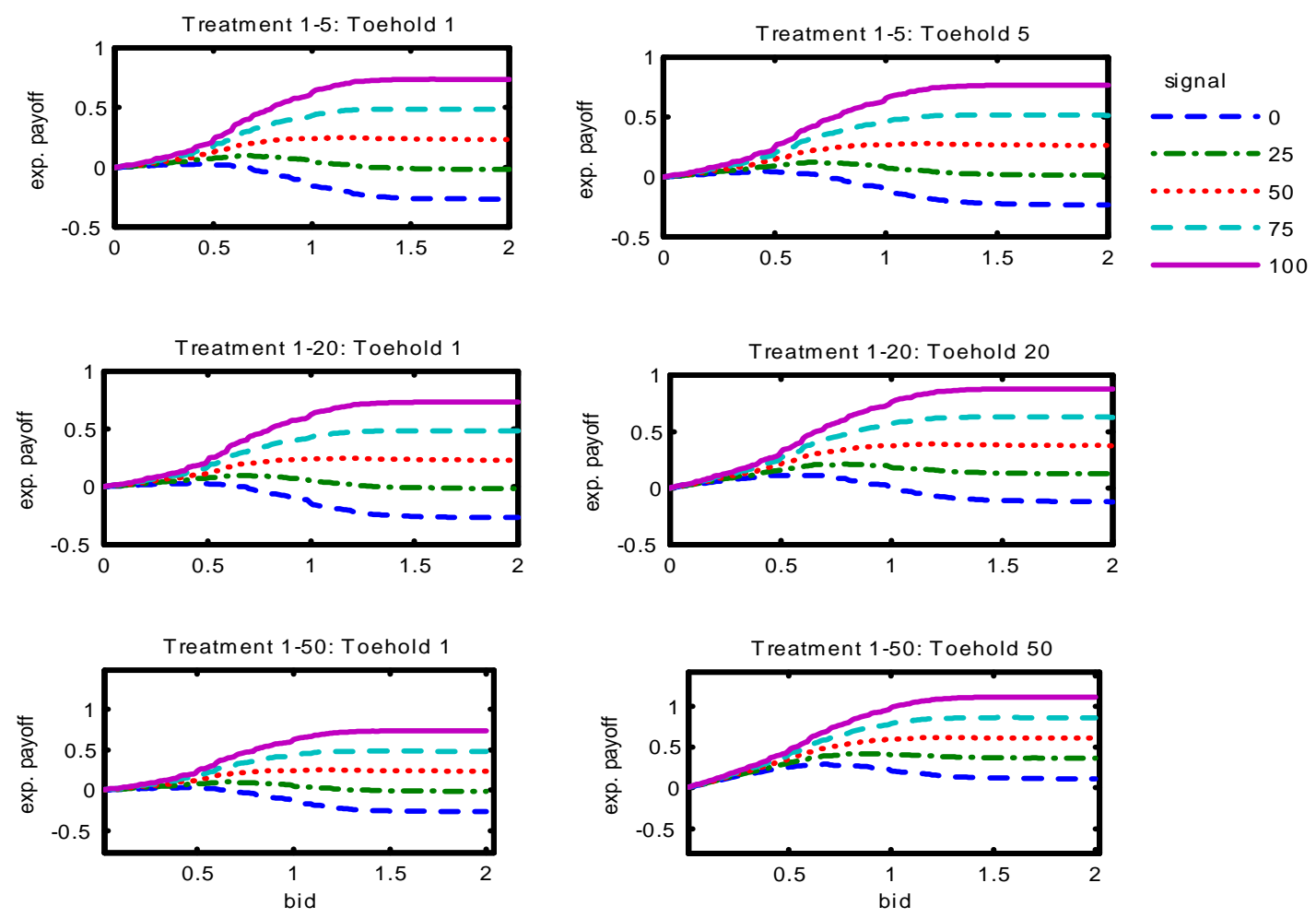

Figure 8: Payoff functions given the actual behaviour in the various treatments. The various curves depict expected profits depending on bids (both scaled by 100) for signals $0,25,50,75$ and 100. 


\subsubsection{Bounded rationality}

As the shape of the payoff functions is leading to deviations from equilibrium, one could use an equilibrium concept that incorporates the ideas of subjects being influenced by the exact shape of payoff functions. In particular, we could calculate a quantal response equilibrium (McKelvey and Palfrey 1995), where players put weights on their strategies that are proportional in some way to the expected payoff from each action. Unfortunately the calculation of a QRE in auctions with continuous strategy spaces is to date generically impossible. An approximation using a discrete version of the game with a 10x10 bidding space, shows that the QRE would go in the direction we observed.

Given that payoffs are very flat, any kind of learning model would predict very slow convergence to the equilibrium. So instead of an equilibrium concept it is interesting to use an explanation that assumes bounded rationality and does not expect subjects to reach an equilibrium, such as a levels of reasoning model (see Nagel 1995, Stahl and Wilson 1995, Camerer 2004, Crawford and Iriberri 2008). Suppose there exist some Level 0 players who are completely irrational and play randomly. Then the expected payoff of a Level 1 (L1) player who anticipates this behaviour is:

$$
\Pi_{i}\left(b_{i}\right)=\operatorname{Pr}\left\{b_{i}>b_{j}\right\} E\left[t_{i}+t_{j}-\left(1-\theta_{i}\right) p \mid b_{i}>b_{j}\right]+\operatorname{Pr}\left\{b_{i} \leq b_{j}\right\} E\left[\theta_{i} p \mid b_{i} \leq b_{j}\right]
$$

Since Level 0 bids randomly with a uniform distribution

$$
\Pi_{i}\left(b_{i}\right)=0.5 b_{i}\left[t_{i}+0.5-0.5\left(1-\theta_{i}\right) b_{i}\right]+\left(1-0.5 b_{i}\right) \theta_{i} b_{i}
$$

Maximization for a Level 1 player leads to following best response bidding function:

$$
b_{L 1}(t, \theta)=\frac{1}{1+\theta_{i}} t_{i}+\frac{0.5+2 \theta_{i}}{1+\theta_{i}}
$$

Note that for a toehold of zero, L1 means the player bids the expectation of the other type's signal (0.5) plus her own signal, that is just her expectation for the total value of the company. As toeholds become bigger the constant part of the bidding function rises above 0.5 and the slope falls. Another interesting feature is that for L1 players the size of the opponent's toehold is irrelevant. This is quite intuitive as L1 players do not follow the chain of reasoning that leads to a Nash equilibrium, where bids are usually dependent on the best responses of the others (except if there 

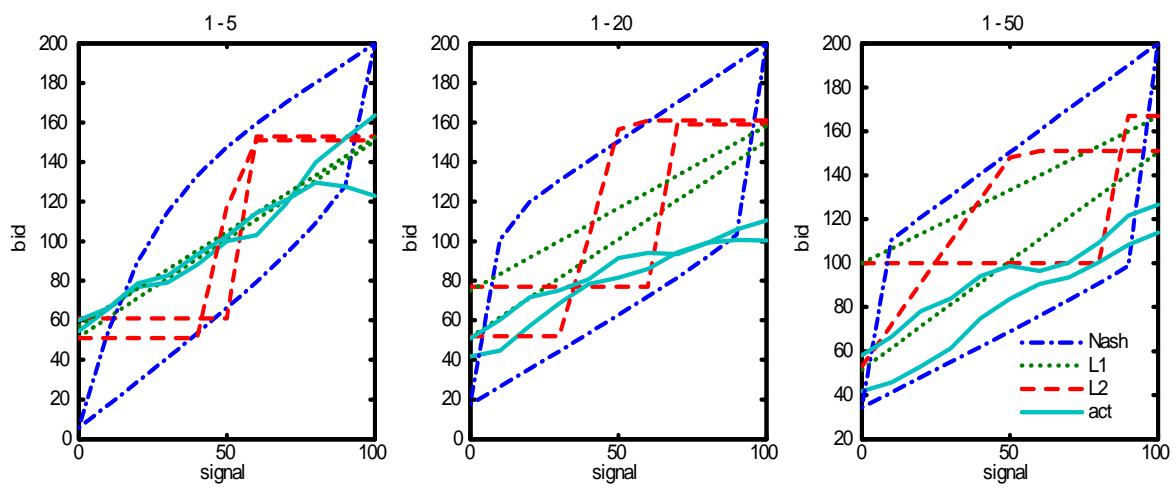

Figure 9: Levels of reasoning: actual behaviour vs the Nash prediction and the Level 1 and 2 models.

exists a dominant strategy). In Figure 9 we observe that L1 fits our experimental results rather well in treatment 1-5, much better than the Nash prediction. For treatments 1-20 and 1-50, recall that the bids of the winner are censored. As the high type tends to win more often in these treatments the observed exits tend to be more downwardly biased than the underlying bidding strategy. If instead of the observed exits we use the results of the censored regression from table 2, L1 describes the high type's strategies better than the Nash prediction.

What is missing however is an explanation of the fact that some low toehold types tended to bid a bit less aggressively in treatment 1-50 and 1-20 than in 1-5. Such an effect can be explained when we examine the bidding strategy of level 2 players, who best respond to the bidding strategies of L1. The calculation of these strategies is not so simple as above and Level 2 players do not use a linear strategy like L1. However, as expected, they do respond to the L1 players in a way that makes low toehold types bid less the higher the toehold of their opponent.

We fit the levels of reasoning model to the data, assuming that the population consists of a mixture of L1 and L2 types, as is found in most experiments in the literature. The model has two parameters, the frequency of the L1 types which is $\mu$ and the SD of the normally distributed errors $\sigma$ which we assume is equal for both types ${ }^{11}$. We also fit the unique Nash equilibrium model assuming normally distributed errors with a SD of $\sigma$. A comparison of the models follows in table 4.

\footnotetext{
${ }^{11}$ In the presented estimations we forced the individual mixture of levels to be equal to the overall frequency in the population for the same type in the same treatment. We have done calculation with individual estimation of the level and the fit was not enhanced by much, but the number of free parameters grows by the number of subjects. Thus we preferred the more parsimonious model. However it is of interest that the type frequencies found with individual estimation where quite close to previous results at ca. 0.05 for L0, 0.6 for L1 and 0.35 for L2.
} 


\begin{tabular}{lllllll}
\hline \hline & $\mathbf{1 - 5}$ & $\mathbf{5 - 1}$ & $\mathbf{1 - 2 0}$ & $\mathbf{2 0 - 1}$ & $\mathbf{1 - 5 0}$ & $\mathbf{5 0 - 1}$ \\
\hline Nash - LL & 798.87 & 864.32 & 1744.0 & 1581.1 & 2999.8 & 1734.3 \\
$\sigma$ & 44.81 & 42.8 & 32.91 & 62.11 & 26.07 & 55.56 \\
\hline mixed L1+L2 -LL & 709.08 & 758.49 & 1742.2 & 1437.5 & 3125.5 & 1610.5 \\
$\sigma$ & 24.92 & 22.71 & 32.74 & 37.52 & 31.72 & 37.67 \\
$\mu$ & 0.9316 & 0.9781 & 1 & 0.8591 & 1 & 0 \\
\hline \hline
\end{tabular}

Table 4: Maximized log likelihoods for the Nash and LOR models.

Overall the mixed L1+L2 model performs better than the Nash prediction and the estimation of the mixture parameter $\mu$ is similar across types and treatments. A serious outlier is found in the case of toehold 50 in treatment 1-50. We think the explanation is to be found within the fact that this case suffers most from the aforementioned unobservable final bid problem.

\subsection{Does a toehold grant its holder a real advantage?}

We can now answer the question if a toehold is beneficial for its holder, at least in the lab. There are two ways to view this, from the ex ante or from the ex post viewpoint.

In the interim stage, where the company has bought the toehold and is preparing for the acquisition, all the investment the company initially made to buy the toehold is a sunk cost. So the only important questions is: does a toehold raise my chances to win in the auction? Does the expected price fall? As we have seen, the answer is positive in both cases. The bidding in the various experiments depends on the size of the available toeholds. Although the high toehold type does not always win (especially not in treatment 1-5), the auction prices fall monotonically in the size of the high type's toehold. This means the presence of a bidder with a high toehold benefits both bidders, usually asymmetrically, and lowers the revenue that the seller can expect. The choice of what toehold to have is fairly clear cut. As we see in Figure 10, the bidders with a toehold of 50 fared better than the others for almost any private value they had.

The ex ante discussion is a bit more complicated. In particular, it is not generally known how the bidder acquired the toehold in the first case. Let us assume that the price per share paid by the prospective owner of the toehold was reflecting the true value of the company ${ }^{12}$, so that for example a $50 \%$ toehold of a company of value 100 would have cost exactly 50. Assume additionally

\footnotetext{
${ }^{12}$ This assumption can be justified, if we suppose that shares of the object under sale were floated in financial markets. Then in these markets some informed investors would drive the price to the true value of the company, as in Kyle 1989.
} 


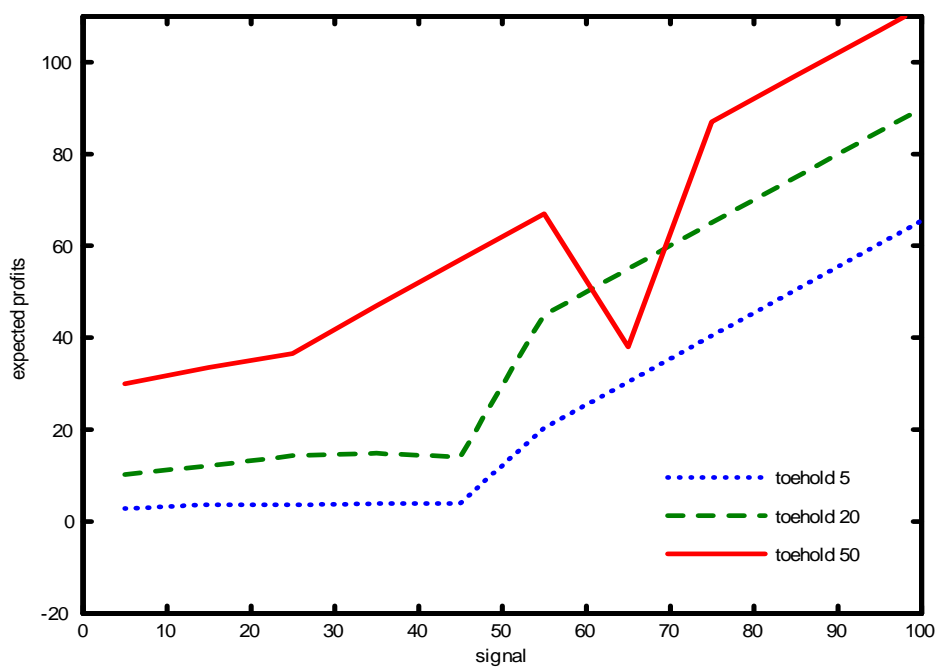

Figure 10: Average profits of holders of toeholds 5 (low curve), 20 and 50 (highest curve) in our experiments for different signals.

that each bidder got a signal of 50. Then we find that buying this toehold was a wise choice for this bidder in case he wins the auction as he gets the rest of the company for only ca. 40 (as we can see in Figure 2), but a suboptimal choice in case he loses, as he would just get ca. 40 for his share of the company, leaving him with a loss of 10 .

In general given the average behaviour of subjects in our experiments we can calculate the expected profit for a bidder with a signal $X$ if he buys a toehold of 5,20 or 50 and given that the other bidder has a toehold of 1 . The results are depicted in Figure 11. The difference between the ex ante and ex post cases is just the inclusion of the payment for the toehold ${ }^{13}$.

We now see the results are now reversed! Acquiring a toehold of 50 is almost never a good strategy. For low signals all toeholds are quite close, but for signals higher than 50 a toehold of 20 is always the best choice.

We could assume a different setup. Imagine the players acquire the toeholds before the private signals are drawn. The player does not know his own private signal and thus the only information available is the expected value of the company, which equals 100 . Then a $5 \%$ toehold would cost exactly 5, a $20 \%$ would cost 20 and a $50 \%$ toehold would cost 50 . The results with the toehold

\footnotetext{
${ }^{13}$ We calculated these expected payoffs assuming that the signal of the other bidder is unknown. Thus we just take its expectation which is equal to 50. It it is of course conceivable that a bidder knows the signal of the other bidder (or has an estimate thereof), but this would completely change the game.
} 


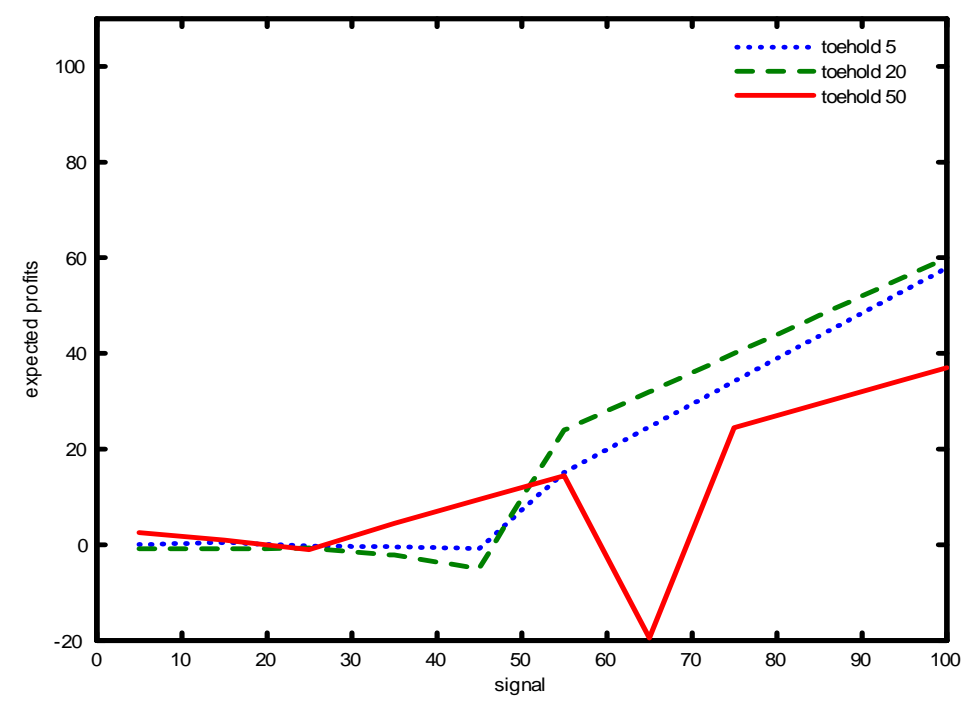

Figure 11: Average profits of bidders holding a toehold of 5, 20 and 50, including the expenditure to acquire the toehold, calculated with method 1 (see text).

prices calculated with this method, are illustrated in Figure 12.

The image is similar to the one above in Figure 11, with the difference that toehold 50 becomes more attractive for high signals and less attractive for low signals. Still in each case we conclude that acquiring a high toehold can sometimes be too costly.

\subsection{Toeholds and almost common values}

Almost common values can be seen as a limit case of the more general toehold framework. In an almost common value auction all but one subjects have the same common value, that is they possess a toehold of zero. The last person has an advantage over the common value, that is, a positive toehold. As the probability of winning in the two person toehold game is equal to $\theta_{i} /\left(\theta_{i}+\theta_{j}\right)$ in the limiting case of almost common values the strong type wins with probability one!

The size of the private advantage of the strong type, that is the size of his toehold, does not influence her probability of winning theoretically. However Rose and Kagel (2006) find that bidders do not follow the strategies predicted by the explosive equilibrium. The authors find that advantaged bidders won only $27 \%$ of the auctions, where $25 \%$ would be predicted by chance factors alone. Additionally there was no significant change in average revenue compared to a series of pure 


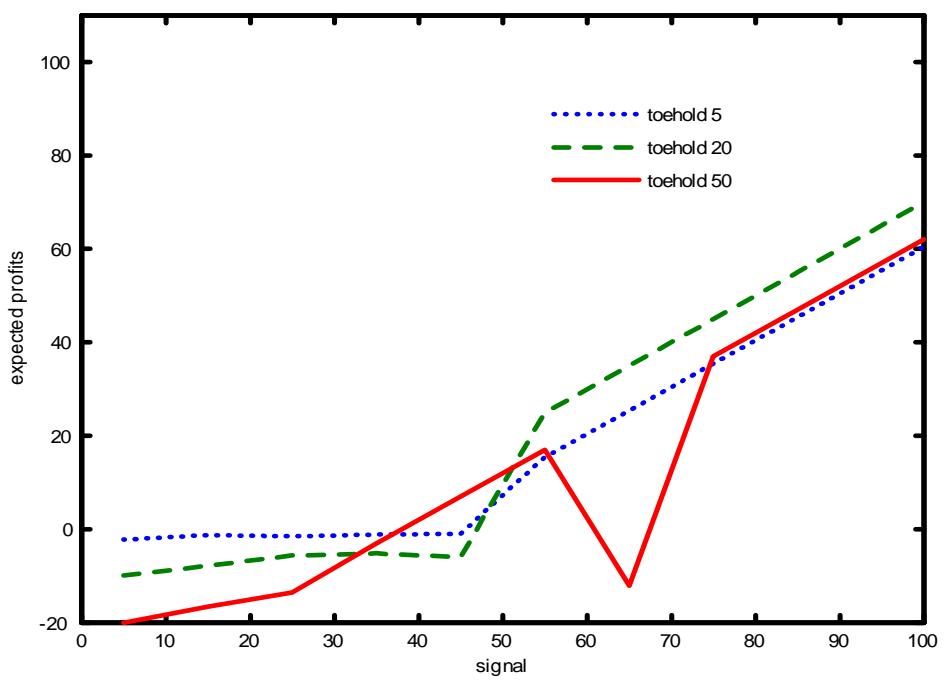

Figure 12: Average profits of bidders holding a toehold of 5, 20 and 50, including the expenditure to acquire the toehold, calculated with method 2 (see text).

common value English auctions.

Combining our results with these findings leads to the following hypothesis: the explosive equilibria are not to be found in real markets. At and close to these equilibria, payoffs are extremely flat, which means subjects have no pressure to play the predicted strategies. Instead they seem to be playing a naive linear strategy. The explanation of Rose and Kagel that the strong type just adds her private advantage to her signal and proceeds to bid like in a pure common value auction, seem to be a plausible first explanation, similar to our L1 model. There is however a feature that remains unexamined: how is the low type playing, how does he respond to a variation of the high type's private advantage? We claim the low type will bid lower the higher the toehold of the opponent, as predicted by the L 2 model. Thus, we can make a testable prediction for almost common value auctions. The winning probability of the high type should not be independent of her private advantage as predicted by theory. This is the case because as Rose and Kagel predict, the high type will be more aggressive but critically the probability will also rise because the low type as in our experiments will become less aggressive in his bidding behavior. This effect however does not converge to the explosive bidding as predicted because due to the flat payoffs subjects do not have sufficient monetary incentives to follow such a counterintuitive strategy. 


\section{Conclusions}

We have found that higher toeholds do raise the probability of winning and the profits of their owners. Moreover the seller's revenue tends to fall the higher the discrepancy between the two players' toeholds. However, this fall is not linear, which means that the revenues fall faster when the toeholds are small than when they are greater. We additionally find that these results are not as strong as predicted by theory, although they are broadly in the right direction. Importantly, we show that the high deviations from equilibrium bids are not reflected in high differences of payoffs between actual and equilibrium payoffs, which could thus be an explanation of the subjects' behaviour. Our results have some implications for the seller. When one player has a small toehold, it might be of benefit to the seller to award the other buyer some shares to level the playing field.

In general we conclude that small toeholds are not very effective when we observe real human players, in contrast to the theory which predicts a very high effect of even the smallest toeholds. On the other hand, we have seen that big toeholds give their owners a significant advantage in the laboratory. Our result is in support of the empirical literature which finds acquiring companies owning sometimes quite large toeholds. This observation is contrary to the theory which predicts a small advantage would do as well and contrary to the strategic thought which says potential buyers should avoid signalling their intentions by prematurely buying too big shares of the company. Finally, although we find big toeholds to be effective, we show that, under some circumstances, acquiring such large toeholds might be too costly and their cost might not be justified by the advantage one gets in the subsequent bidding for the control of the company.

\section{References}

[1] Avery, Christopher and John H. Kagel, 1997. "Second-Price Auctions with Asymmetric Payoffs: An Experimental Investigation," Journal of Economics 85 Management Strategy, Blackwell Publishing, vol. 6(3), pages 573-603, 09.

[2] Betton, Sandra and B. Espen Eckbo, 2000 "Toeholds, Bid Jumps, and Expected Payoffs in Takeovers" Review of Financial Studies, vol. 13 (4), pages 841-882 
[3] Bulow, Jeremy; Ming Huang and Paul Klemperer, 1999. "Toeholds and Takeovers", Journal of Political Economy, University of Chicago Press, vol. 107(3), pages 427-454

[4] Camerer, Colin; Teck-Hua HO; and Juin-Kuan Chong 2004: "A Cognitive Hierarchy Model of Games," Quarterly Journal of Economics, 119, 861-898.

[5] Crawford, Vincent and Nagore Iriberri 2008 "Level-k Auctions: Can a Non-Equilibrium Model of Strategic Thinking Explain the Winner's Curse and Overbidding in Private-Value Auctions?," Econometrica, forthcoming

[6] Dyck, Alexander and Luigi Zingales, 2004. "Private Benefits of Control: An International Comparison," Journal of Finance, American Finance Association, vol. 59(2), pages 537-600, 04.

[7] Fischbacher, Urs 2007 z-Tree: Zurich Toolbox for Ready-made Economic Experiments, Experimental Economics 10(2), 171-178.

[8] Harrison, Glenn 1989 "Theory and Misbehavior of First-Price Auctions", American Economic Review, 79, 749-762

[9] Kagel, John H and Dan Levin 2003 "Almost Common-Value auctions revisited", European Economic Review

[10] Kagel, John H and Susan Rose 2006 "Bidding in Almost Common Value Auctions: An Experiment", working paper

[11] Kirchkamp, Oliver and Benny Moldovanu, 2004 "An experimental analysis of auctions with interdependent valuations", Games and Economic Behavior, Vol. 48 (1), July, pp. 54-85

[12] McKelvey, Richard R. and Thomas R. Palfrey 1995 "Quantal Response Equilibrium for Normal Form Games", Games and Economic Behavior 10, 6-38

[13] Nagel, Rosemarie, 1995, "Unraveling in Guessing Games: An Experimental Study", American Economic Review, American Economic Association, vol. 85(5), pages 1313-26, December. 
[14] Pagano, Marco, Fabio Panetta and Luigi Zingales, 1998. "Why Do Companies Go Public? An Empirical Analysis", Journal of Finance, American Finance Association, vol. 53(1), pages $27-64,02$

[15] Stahl, Dale and Paul Wilson 1995: "On Players' Models of Other Players: Theory and Experimental Evidence", Games and Economic Behavior, 10, 218-254. 